\title{
RANCANG BANGUN ANTENA MIKROSTRIP PERSEGI PANJANG 2,4 GHZ UNTUK APLIKASI WIRELESS FIDELITY (WI-FI)
}

\author{
Eva Yovita Dwi Utami*, F. Dalu Setiaji, Daniel Pebrianto \\ Program Studi Teknik Elektro, Universitas Kristen Satya Wacana \\ *Corresponding author, e-mail: eva.utami@staff.uksw.edu ${ }^{1}$
}

\begin{abstract}
Abstrak - Untuk mendukung teknologi Wi-Fi diperlukan antena berbiaya murah yang berukuran kecil serta mudah diintegrasikan dengan peralatan lain. Untuk itu antena mikrostrip menjadi kandidat utamanya. Pada makalah ini, dirancang antena mikrostrip patch persegi panjang yang bekerja pada frekuensi $2,4 \mathrm{GHz}$ $(2,4-2,49 \mathrm{GHz})$. Untuk meningkatkan gain, dirancang antena array dua elemen. Hasil pengukuran menunjukkan, antena mikrostrip elemen tunggal bekerja pada rentang frekuensi $2,4-2,5 \mathrm{GHz}$ (bandwidth $100 \mathrm{MHz}$ ) dengan VSWR $\leq 1,92$ dan mempunyai gain 3,9 dB. Sedangkan antena mikrostrip array dua elemen mampu bekerja pada rentang frekuensi 2,35 - 2,5 GHz (bandwidth $150 \mathrm{MHz}$ ) dengan VSWR $\leq$ 1,497 dan memiliki gain lebih besar yaitu $6,67 \mathrm{~dB}$. Level sinyal daya terima perangkat mobile pada saat Wi-Fi router menggunakan antena array dua elemen yang dirancang, lebih baik dibandingkan dengan pada saat menggunakan antena dipole atau antena mikrostrip elemen tunggal.
\end{abstract}

Kata Kunci :Mikrostrip, patch persegi panjang, Wi-Fi

\begin{abstract}
To support Wi-Fi technology, a low cost antenna which has small size and easily integrated with other device is required. Therefore, microstrip antenna becomes the main candidate. In this paper, design of rectangular patch microstrip antennas which work at the frequency of $2.4 \mathrm{GHz}(2.4-2.49 \mathrm{GHz})$ is presented. To increase gain, we designed a two-elements rectangular patch microstrip array antenna. The measurement of the designed antenna shows that the single patch microstrip antenna is capable of working at frequency range of $2.4-2.5 \mathrm{GHz}$ with VSWR $\leq 1.92$ and only has $3.9 \mathrm{~dB}$ gain, while two elements rectangular patch array microstrip antenna is capable of working at frequency range of $2.35-2.5 \mathrm{GHz}$ with VSWR $\leq 1.497$ and gain of $6.67 \mathrm{~dB}$. Received signal level on a mobile device when this 2-elements array antenna installed on a $\mathrm{Wi}-\mathrm{Fi}$ is higher than if a dipole or a single patch antenna is installed instead.
\end{abstract}

Keywords : microstrip, rectangular patch, Wi-Fi

Copyright $\odot 2017$ JNTE. All rights reserved

\section{PENDAhuluaN}

Pada sistem komunikasi nirkabel dibutuhkan antena dalam proses transmisi data ke dan dari udara, agar gelombang elektromagnetik dapat dipancarkan dan diterima secara efektif. Salah satu teknologi komunikasi nirkabel adalah Wireless Local Area Network (WLAN) yang diaplikasikan pada area lokal misalnya dalam satu gedung atau satu kantor. Terdapat dua alokasi frekuensi yang digunakan yaitu $2,4 \mathrm{GHz}$ dan $5 \mathrm{GHz}$. Frekuensi $2,4 \mathrm{GHz}$ digunakan oleh standar protokol IEEE $802.11 \mathrm{~b} / \mathrm{g}$ untuk wireless fidelity (Wi-Fi). Kanal frekuensi Wi-Fi dibagi menjadi 14 saluran sebagaimana dijelaskan dalam [1].

Kekuatan sinyal Wi-Fi bervariasi terhadap tempat, sehingga dimungkinkan terdapat sejumlah tempat yang sinyalnya lemah sehingga membutuhkan antena dengan gain tinggi. Dalam mendesain antena tersebut, ukuran dan biaya pembuatan juga harus dipertimbangkan.

Antena mikrostrip dapat memberikan solusi karena ukurannya yang kecil, ringan, harganya murah, dapat difabrikasi oleh teknologi printedboard modern serta mudah diintegrasikan dengan microwave integrated circuits (MICs) [2],[3]. Namun antena tersebut memiliki efisiensi dan gain yang relatif kecil sehingga harus digunakan metode-metode tertentu untuk meningkatkannya, misalnya dengan menyusun elemen antena dalam bentuk array.

Salah satu bentuk antena mikrostrip yang banyak digunakan dan mudah dianalisis adalah patch persegi panjang. Pada [4], telah dirancang antena mikrostrip segi empat elemen tunggal pada frekuensi 2,4 GHz dengan bandwidth 112 $\mathrm{MHz}$ dan gain $6 \mathrm{~dB}$. Sedangkan pada 
perancangan antena mikrostrip 2,4 GHz dengan metode pencatuan EMC (Electromagnetically Coupled) [5], diperoleh gain pada frekuensi 2,45 $\mathrm{GHz}$ sebesar $9 \mathrm{~dB}$, namun tidak dilaporkan bandwidth yang berhasil didapatkan. Antena mikrostrip persegi panjang juga dirancang untuk aplikasi GPS pada frekuensi 1575,42 sebagaimana dilaporkan dalam [6], dengan gain yang diperoleh adalah $3,451 \mathrm{~dB}$. Rancang bangun antena mikrostrip segiempat dua susun untuk aplikasi Wi-Fi dilaporkan pada [7] dengan gain berdasarkan simulasi (tanpa pengukuran) diperoleh sebesar 9,377 dB. Modifikasi antena lainnya untuk aplikasi Wi-Fi telah disajikan juga dalam [8] yaitu berupa antena biquad ganda dengan hasil bandwidth sebesar $555 \mathrm{MHz}$.

Dalam makalah ini dilaporkan perancangan antena mikrostrip patch persegi panjang dengan menggunakan satu elemen (elemen tunggal) dan juga dua elemen untuk meningkatkan gain-nya. Antena dirancang untuk bekerja pada frekuensi kerja Wi-Fi yaitu 2,401-2,495 GHz, dengan teknik pencatuan inset fed. Antena yang telah difabrikasi kemudian diukur untuk mengetahui nilai parameter kinerja antena dan diujikan pada perangkat Wi-Fi.

\section{TINJAUAN PUSTAKA}

Antena mikrostrip didefinisikan sebagai salah satu jenis antena yang mempunyai bentuk seperti bilah dengan ukuran sangat tipis. Struktur dasar antena mikrostrip terdiri atas patch peradiasi, dielektrik substrat dan ground plane seperti ditunjukkan pada Gambar 1.

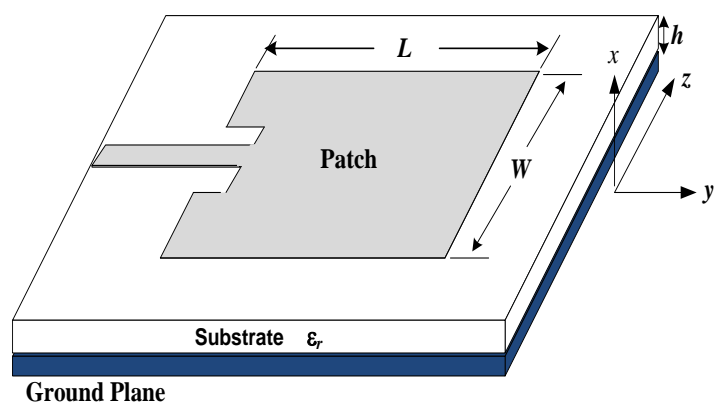

Gambar 1. Struktur sebuah antena mikrostrip[2].

Elemen peradiasi (patch) dibuat dari logam dan memiliki ketebalan tertentu dan berfungsi meradiasikan gelombang elektromagnetik. Patch terletak paling atas dari keseluruhan sistem antena. Jenis logam yang biasa digunakan adalah tembaga dengan konduktivitas 5,8 x $10^{7}$ $\mathrm{S} / \mathrm{m}$.

Elemen substrat (substrate) berfungsi sebagai bahan dielektrikum dari antena mikrostrip yang membatasi elemen peradiasi dengan elemen pentanahan. Elemen ini memiliki jenis yang bervariasi yang dapat digolongkan berdasarkan nilai permitivitas relatif $\left(\varepsilon_{\mathrm{r}}\right)$ dan ketebalan $(h)$. Kedua nilai tersebut mempengaruhi frekuensi kerja, bandwidth, dan juga efisiensi antena yang akan dibuat. Ketebalan substrat jauh lebih besar daripada ketebalan logam peradiasi. Semakin tebal substrat maka bandwidth akan semakin meningkat tetapi akan berpengaruh terhadap timbulnya gelombang permukaan (surface wave) [2].

Bidang pentanahan (ground plane) berfungsi sebagai pembumian bagi sistem antena mikrostrip. Elemen pentanahan ini umumnya memiliki jenis bahan yang sama dengan elemen peradiasi yaitu berupa logam tembaga.

Dalam perancangan antena mikrostrip berbentuk patch persegi panjang, dilakukan perhitungan dimensi antena sesuai $[2,9]$ sebagai berikut.

Untuk menentukan lebar patch digunakan (1)

$$
W=\frac{c}{2 f_{o}} \sqrt{\frac{2}{\left(\varepsilon_{r}+1\right)}}
$$

$W$ merupakan lebar patch, $c$ adalah kecepatan cahaya di ruang bebas yaitu sebesar $3 \times 10^{8} \mathrm{~m} / \mathrm{s}, f_{0}$ adalah frekuensi resonansi antena, dan $\varepsilon_{r}$ adalah permitivitas relatif bahan substrat.

Pertambahan panjang $\Delta L$ akibat adanya fringing effect dirumuskan sebagai berikut ini.

$$
\Delta L=0,412 h \frac{\left(\varepsilon_{r e f f}+0,3\right)\left(\frac{W}{h}+0,264\right)}{\left(\varepsilon_{r e f f}-0,258\right)\left(\frac{W}{h}+0,8\right)}
$$

dengan $h$ adalah tebal substrat, dan $\varepsilon_{\text {reff }}$ adalah permitivitas relatif efektif yang dirumuskan dengan

$$
\varepsilon_{\text {reff }}=\frac{\varepsilon_{r}+1}{2}+\frac{\varepsilon_{r}-1}{2}\left(\frac{1}{\sqrt{1+12 \frac{h}{W}}}\right)
$$

Panjang patch efektif dirumuskan dengan: 


$$
L_{e f f}=\frac{c}{2 f_{o \sqrt{\varepsilon_{\text {reff }}}}}
$$

Maka panjang patch $(L)$ diberikan oleh

$$
L=L_{e f f}-2 \Delta L
$$

Untuk menentukan impedansi karakteristik $\left(Z_{0}\right)$, dilakukan pengaturan lebar saluran mikrostrip. Hal ini terkait dengan impedance matching antara saluran mikrostrip tersebut dengan saluran pencatunya [10].

$\frac{W}{h}=\frac{2}{\pi}\left[B-1-\ln (2 B-1)+\frac{\varepsilon_{r}-1}{\varepsilon_{r}}\{\ln (B-1)+\right.$

$\left.\left.0,39-\frac{0,61}{\varepsilon_{r}}\right\}\right]$

Dengan $B$ diperoleh dari

$$
B=\frac{60 \pi^{2}}{Z_{o} \sqrt{\varepsilon_{r}}}
$$

Sedangkan untuk menentukan panjang saluran pencatu $L_{f}$ menggunakan persamaan sebagai berikut :

$$
\begin{aligned}
& \lambda_{o}=\frac{c}{f_{o}} \\
& \lambda_{g}=\frac{\lambda_{o}}{\sqrt{\varepsilon_{\text {reff }}}} \\
& L_{f}=\frac{\lambda_{g}}{4}
\end{aligned}
$$

Untuk mencapai impedance matching digunakan inset fed pada saluran pencatuan. Panjang inset fed diperoleh dengan perhitungan berikut [11]

$Y_{o}=10^{-4}\left(0,001699 \varepsilon_{r}^{7}+0,13761 \varepsilon_{r}^{6}-\right.$

$6,1783 \varepsilon_{r}^{5}+93,187 \varepsilon_{r}^{4}-682,69 \varepsilon_{r}^{3}+2561,9 \varepsilon_{r}^{2}-$

$\left.4043 \varepsilon_{r}+6697\right) \frac{L}{2}$

\section{METODOLOGI}

Tahapan proses perancangan ditunjukkan pada Gambar 2. Antena yang dirancang diharapkan bekerja pada frekuensi $2,401 \mathrm{GHz}-$ 2,495 GHz. Bahan substrat yang digunakan adalah FR4 Epoxy dengan nilai permitivitas relatif 4,65 dan ketebalan 1,6 $\mathrm{mm}$.

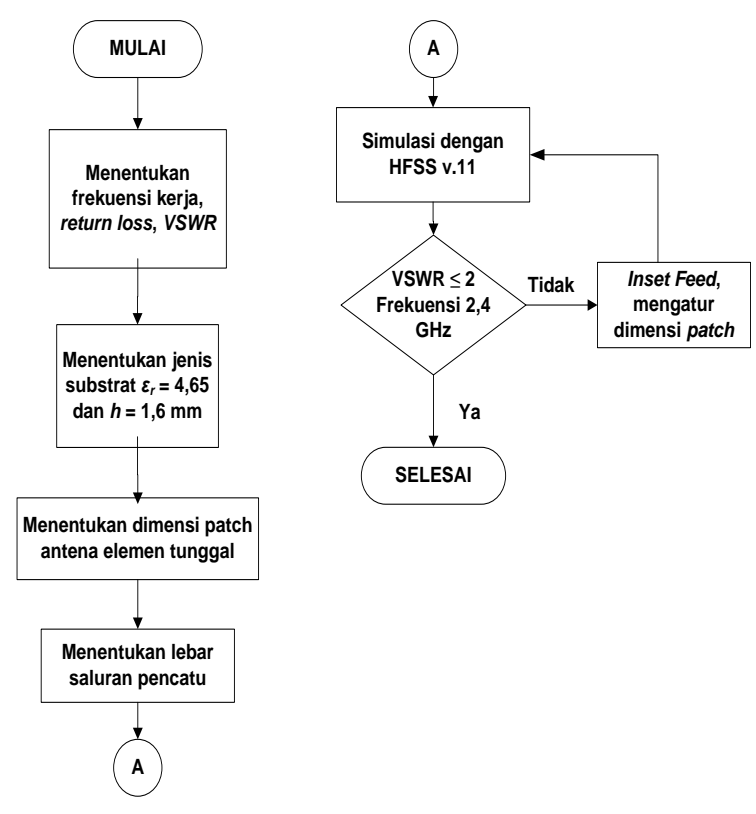

Gambar 2. Diagram alir perancangan patch elemen tunggal

\subsection{Perancangan Antena Elemen Tunggal}

Dengan menggunakan (1) - (7) akan diperoleh panjang dan lebar patch masingmasing sebesar 28,07 $\mathrm{mm}$ dan 36,46 $\mathrm{mm}$. Dengan menggunakan (9)-(10) diperoleh panjang dan lebar saluran pencatu masingmasing 16,4 $\mathrm{mm}$ dan 2,94 $\mathrm{mm}$. Dimensi hasil perhitungan tersebut kemudian diolah menggunakan simulator dan diperoleh bentuk rancangan awal antena seperti pada Gambar 3 .

Dari hasil simulasi awal, frekuensi kerja bergeser ke frekuensi $2,35 \mathrm{GHz}$ dengan nilai VSWR $=2,05$ dan nilai return loss sebesar $-9,22$ $\mathrm{dB}$, sedangkan pada frekuensi 2,4 GHz didapatkan nilai VSWR $=2,3$ dan nilai return loss sebesar $-8,07 \mathrm{~dB}$. Hal tersebut disebabkan ketidaksesuaian antara perhitungan dimensi patch persegi panjang dengan teknik pencatuan inset fed. Maka agar mendapatkan hasil rancangan yang lebih optimal perlu dilakukan perhitungan inset fed menggunakan (11) dan mengubah panjang antena.

Panjang inset fed saluran pencatu terbaik yang dipeoleh sebesar $5 \mathrm{~mm}$. Simulasi antena elemen tunggal menghasilkan dimensi patch dengan ukuran panjang 27,1 mm dan lebar 36,46 $\mathrm{mm}$. Simulasi juga menunjukkan bandwidth yang diperoleh dari rancangan antena tersebut adalah $90 \mathrm{MHz}$ dengan $\mathrm{VSWR} \leq 2$, dan gain $3,75 \mathrm{~dB}$ dalam rentang frekuensi $2,4 \mathrm{GHz}-2,49$ $\mathrm{GHz}$. 


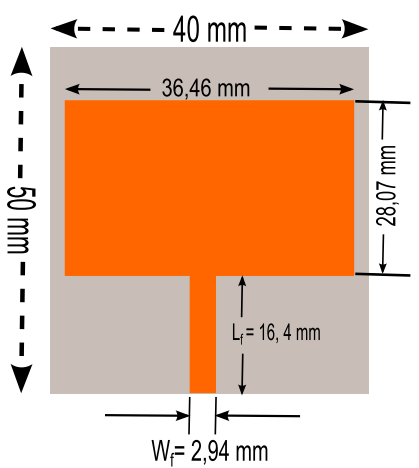

(a)

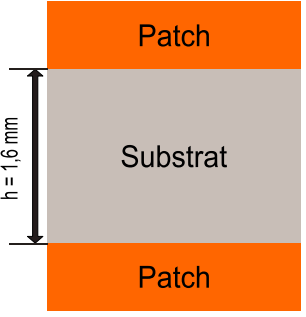

(b)
Gambar 3. Bentuk rancangan awal antena elemen tunggal: (a). Tampilan atas, (b). Tampilan samping

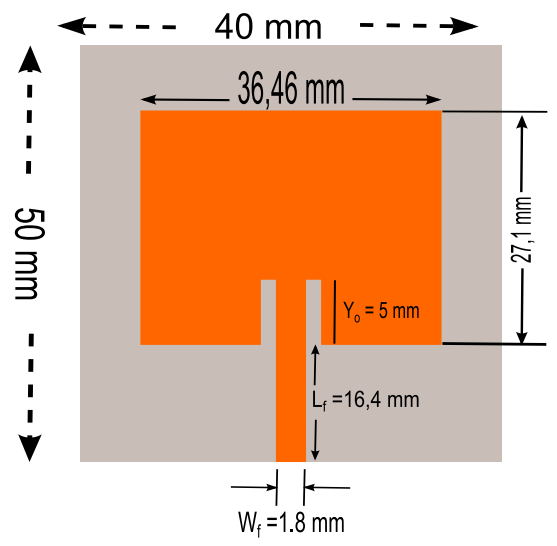

Gambar 4. Bentuk rancangan antena elemen tunggal dengan inset fed

\subsection{Perancangan Array Patch Persegi Panjang Dua Elemen}

Antena yang dirancang menjadi bentuk array didasarkan pada antena patch elemen tunggal yang telah dirancang, yaitu dengan dimensi patch $34,6 \mathrm{~mm} \times 27,1 \mathrm{~mm}$, panjang saluran pencatu $16,4 \mathrm{~mm}$, panjang inset fed 5 $\mathrm{mm}$ dengan jarak antar elemen sebesar N4=30,64 mm, dan menggunakan T-Junction dengan impedansi 70,711 $\Omega$. Dimensi dan parameter-parameter tersebut disimulasikan dalam software.

Hasil simulasi rancangan awal tersebut belum memenuhi nilai parameter VSWR, return loss, dan frekuensi resonansi yang diinginkan. Untuk mendapatkan nilai yang optimal maka dilakukan simulasi dengan mengubah-ubah panjang dan lebar patch sampai diperoleh frekuensi resonansi $2,45 \mathrm{GHz}$ pada parameter VSWR dan return loss terbaik. Panjang dan lebar antena yang didapatkan 27,7 mm dan 36,36 $\mathrm{mm}$, sehingga bentuk rancangan antena dan dimensinya menjadi seperti diperlihatkan pada Gambar 5. Antena array dua elemen tersebut menghasilkan bandwidth sebesar $90 \mathrm{MHz}$, $\mathrm{VSWR} \leq 2$, dan gain sebesar $5,72 \mathrm{~dB}$ pada rentang frekuensi $2,4 \mathrm{GHz}-2,49 \mathrm{GHz}$

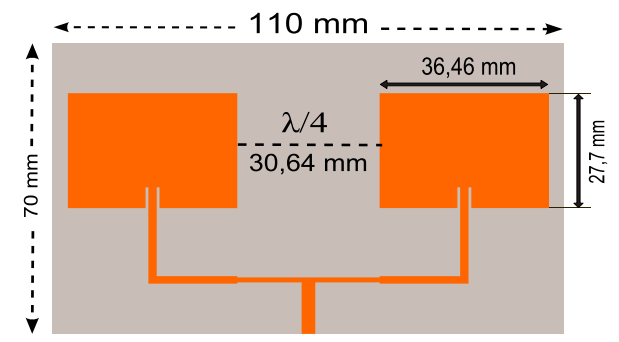

Gambar 5. Bentuk rancangan antena array dua elemen

\section{HASIL DAN PEMBAHASAN}

Rancangan antena hasil simulasi kemudian difabrikasi dengan bahan substrat FR4 Epoxy, sehingga didapatkan bentuk antena seperti pada Gambar 6.

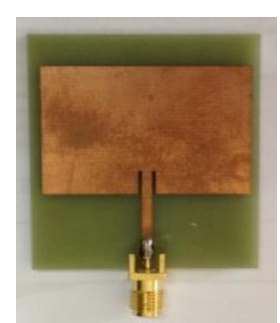

(a)

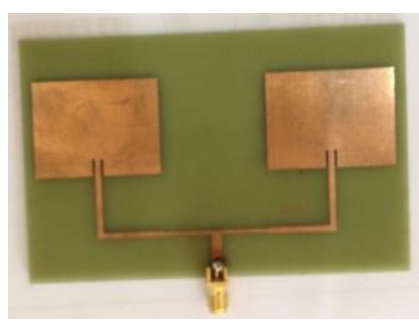

(b)
Gambar 6. Antena hasil fabrikasi (a) elemen tunggal (b) dua elemen

Untuk menguji hasil rancangan, dilakukan pengukuran pada antena yang telah difabrikasi menggunakan Spectrum Analyzer dan Network Analyzer. Parameter yang diukur adalah VSWR, return loss, impedansi antena, pola radiasi dan gain.

Pada pengukuran antena elemen tunggal didapatkan nilai VSWR dan return loss terbaik sebesar 1,055 dan $-31,444 \mathrm{~dB}$ pada frekuensi 2,45 GHz. Nilai Bandwidth pada saat VSWR $\leq 2$ adalah sebesar $100 \mathrm{MHz}$ yaitu pada rentang frekuensi 2,4 GHz sampai 2,5 GHz. Nilai VSWR dan return loss masing-masing batas frekuensi 
adalah sebesar 1,92 dan $-10,028 \mathrm{~dB}$ (pada 2,4 $\mathrm{GHz}$ ) serta 1,888 dan $-10,243 \mathrm{~dB}$ (pada 2,5 $\mathrm{GHz}$ ). Hasil pengukuran VSWR dan return loss ditunjukkan pada Gambar 7 dan 8. Nilai impedansi antena elemen tunggal terukur adalah sebesar $47,755 \Omega$.

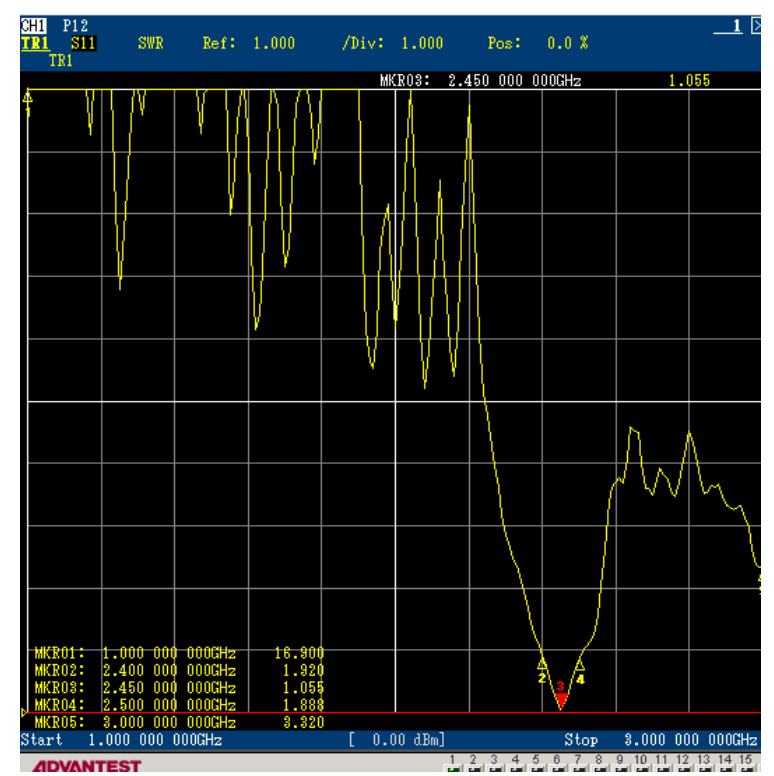

Gambar 7. Grafik hasil pengukuran VSWR antena elemen tunggal

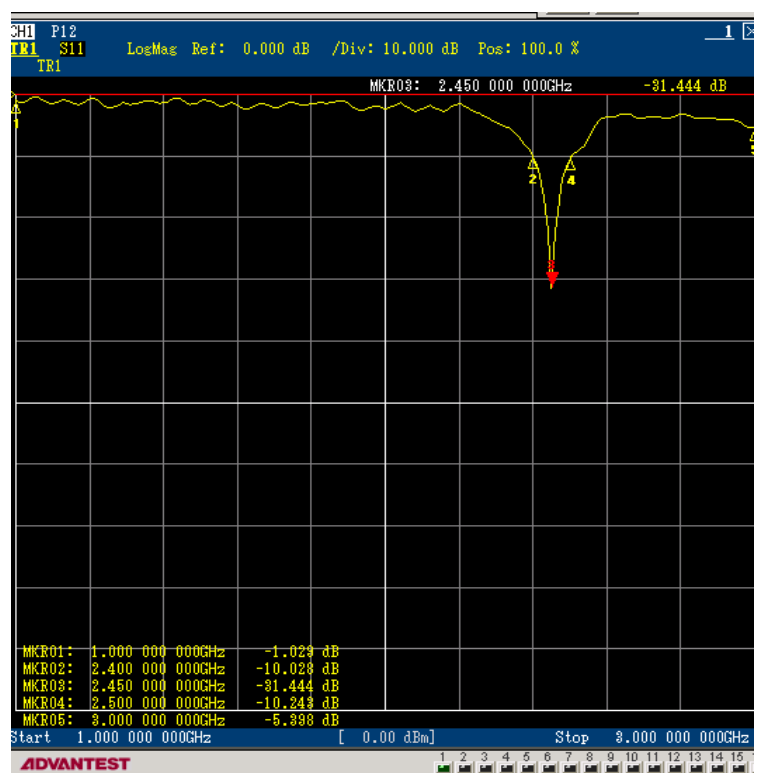

Gambar 8. Grafik hasil pengukuran return loss antena elemen tunggal

Selanjutnya pada pengukuran antena array dua elemen didapatkan nilai VSWR dan return loss terbaik sebesar 1,036 dan -34,929 dB pada frekuensi 2,45 GHz. Hal ini ditunjukkan pada Gambar 9 dan 10.

Nilai Bandwidth pada saat VSWR $<1,5$ (lebih baik dibandingkan elemen tunggal) adalah sebesar $150 \mathrm{MHz}$ yaitu pada rentang frekuensi 2,35 GHz sampai 2,5 GHz. Nilai VSWR dan return loss masing-masing batas frekuensi adalah sebesar 1,471 dan $-14,387 \mathrm{~dB}$ (pada 2,35 GHz) serta 1,497 dan $-14,016 \mathrm{~dB}$ (pada 2,5 $\mathrm{GHz}$ ). Nilai impedansi antena dua elemen ini adalah sebesar $51,716 \Omega$.

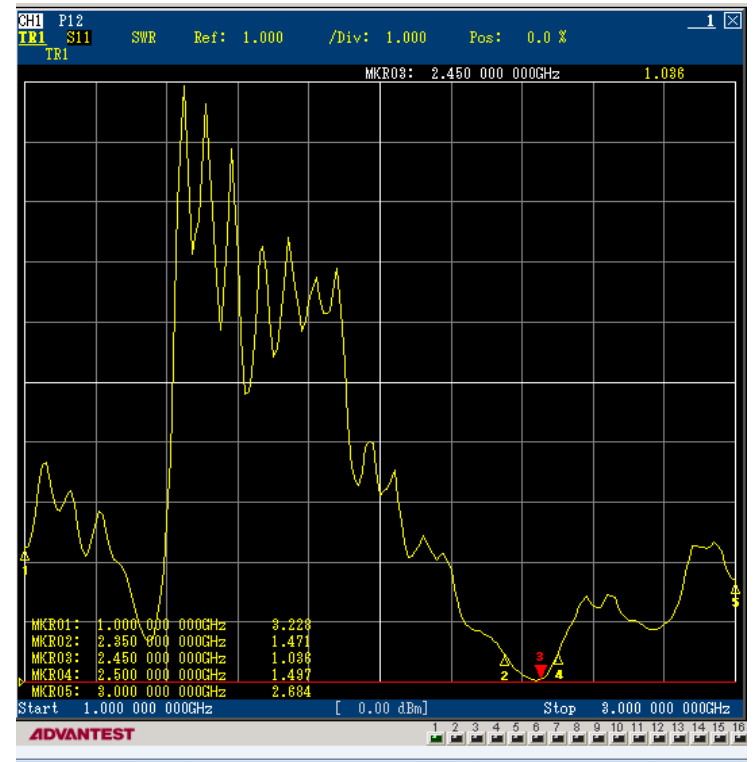

Gambar 9. Grafik hasil pengukuran VSWR antena array dua elemen

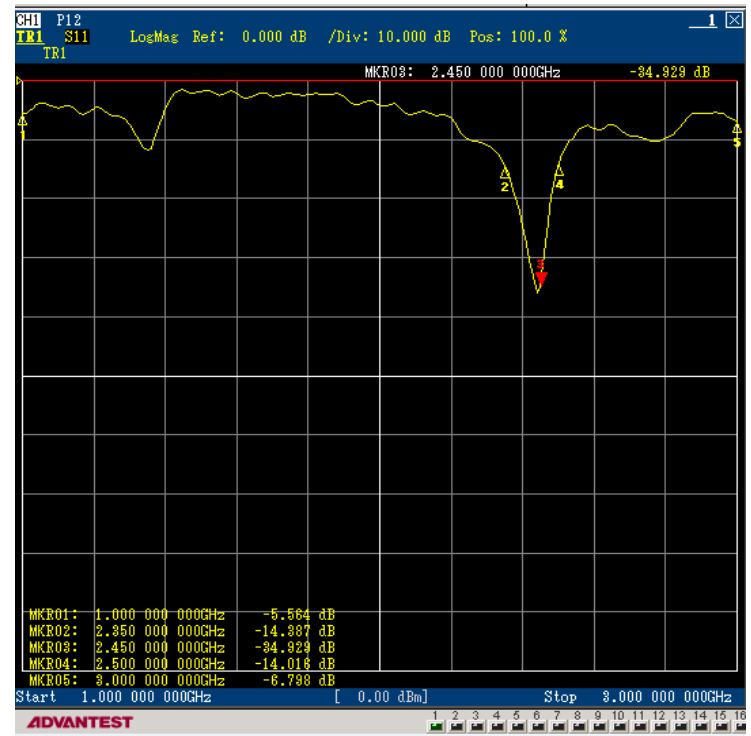

Gambar 10. Grafik hasil pengukuran return loss antena array dua elemen 
Gambar 11 dan 12 menunjukkan pola radiasi daya pada kedua antena mikrostrip persegi panjang yang telah dirancang. Keduanya menunjukkan pengarahan maksimum pada sudut $0^{\circ}$ dan pola radiasi direksional.

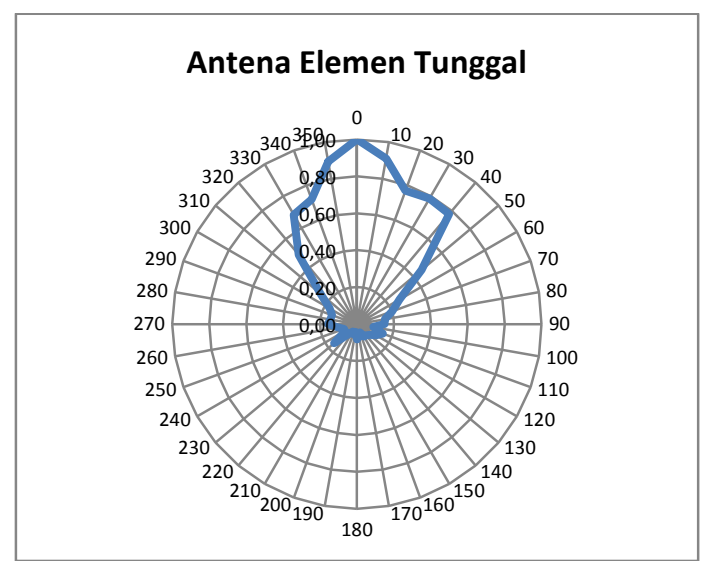

Gambar 11. Pola radiasi antena elemen tunggal

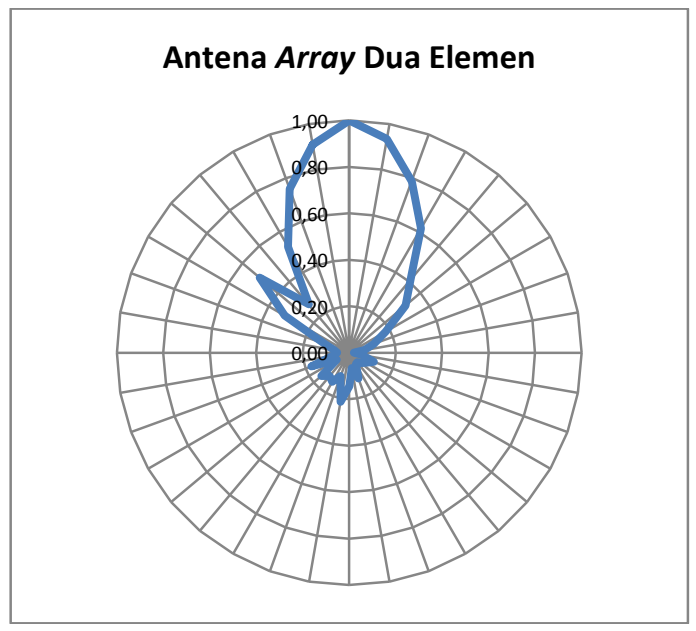

Gambar 12. Pola radiasi antena array dua elemen

Parameter antena yang diukur berikutnya adalah gain. Dari hasil pengukuran menggunakan spectrum analyzer diperoleh gain antena untuk elemen tunggal sebesar 3,9 dB dan untuk antena array dua elemen sebesar 6,67 dB. Hasil pengukuran tersebut ternyata lebih baik dari hasil simulasinya.

Tabel 1 merangkum hasil pengukuran antena yang telah difabrikasi. Dapat dilihat bahwa antena dua elemen memberikan perbaikan kinerja parameter antena yang ditunjukkan oleh nilai VSWR dan return loss yang menurun, sementara bandwidth dan gain antena meningkat
Tabel 1. Hasil Pengukuran Antena

\begin{tabular}{|c|c|c|}
\hline Parameter & $\begin{array}{c}\text { Antena Elemen } \\
\text { Tunggal }\end{array}$ & $\begin{array}{c}\text { Antena array } \\
\text { dua Elemen }\end{array}$ \\
\hline $\begin{array}{c}\text { Rentang } \\
\text { frekuensi kerja }\end{array}$ & $2,4-2,5 \mathrm{GHz}$ & $2,35-2,5 \mathrm{GHz}$ \\
\hline $\begin{array}{c}\text { VSWR dan } \\
\text { Return Loss } \\
\text { pada frekuensi } \\
2,45 \mathrm{GHz}\end{array}$ & $\begin{array}{c}\text { VSWR }=1,055 \\
\text { Return Loss }=- \\
31,444 \mathrm{~dB}\end{array}$ & $\begin{array}{c}\text { VSWR }=1,036 \\
\text { Return Loss }=- \\
34,929 \mathrm{~dB}\end{array}$ \\
\hline $\begin{array}{c}\text { VSWR dan } \\
\text { Return Loss } \\
\text { pada bandwidth }\end{array}$ & $\begin{array}{c}\text { VSWR } \leq 2 \\
\text { Return Loss } \leq- \\
9,54 \mathrm{~dB}\end{array}$ & $\begin{array}{c}\text { VSWR } \leq 1,5 \\
\text { Return Loss } \leq- \\
13,97 \mathrm{~dB}\end{array}$ \\
\hline $\begin{array}{c}\text { Impedance } \\
\text { bandwidth }\end{array}$ & $100 \mathrm{MHz}$ & $150 \mathrm{MHz}$ \\
\hline Gain & $3,9 \mathrm{~dB}$ & $6,67 \mathrm{~dB}$ \\
\hline
\end{tabular}

Pengujian berikutnya adalah dengan memasangkan antena hasil rancangan pada sebuah Wi-Fi router dan mengukur level daya sinyal terima pada perangkat mobile yang menangkap sinyal dari antena Wi-Fi router tersebut. Tabel 2 menunjukkan hasil pengukuran level sinyal daya yang diterima pada saat Wi-Fi router menggunakan antena mikrostrip hasil rancangan. Hasil tersebut dibandingkan dengan level daya terima dari antena dipole.

Tabel 2. Hasil Pengukuran Level Daya Sinyal Terima

\begin{tabular}{|c|c|c|c|}
\hline & \multicolumn{3}{|c|}{ LEVEL SINYAL DAYA TERIMA (dBm) } \\
\hline $\begin{array}{c}\text { Jarak } \\
(\mathrm{m})\end{array}$ & $\begin{array}{c}\text { Dipole (5 } \\
\mathrm{dB})\end{array}$ & $\begin{array}{c}\text { Mikrostrip } \\
\text { Elemen } \\
\text { Tunggal }(3,9 \\
\mathrm{dB})\end{array}$ & $\begin{array}{c}\text { Mikrostrip } \\
\text { Array Dua } \\
\text { Elemen }(6,67 \\
\mathrm{dB})\end{array}$ \\
\hline \multicolumn{4}{|c|}{ Sumber 1 } \\
\hline 2 & $-33 \mathrm{dBm}$ & $-38 \mathrm{dBm}$ & $-32 \mathrm{dBm}$ \\
\hline 4 & $-40 \mathrm{dBm}$ & $-41 \mathrm{dBm}$ & $-39 \mathrm{dBm}$ \\
\hline 7 & $-48 \mathrm{dBm}$ & $-49 \mathrm{dBm}$ & $-47 \mathrm{dBm}$ \\
\hline \multicolumn{4}{|c|}{ Sumber 2 } \\
\hline 2 & $-35 \mathrm{dBm}$ & $-36 \mathrm{dBm}$ & $-32 \mathrm{dBm}$ \\
\hline 4 & $-43 \mathrm{dBm}$ & $-44 \mathrm{dBm}$ & $-40 \mathrm{dBm}$ \\
\hline 7 & $-48 \mathrm{dBm}$ & $-49 \mathrm{dBm}$ & $-46 \mathrm{dBm}$ \\
\hline & & Sumber 3 & \\
\hline 2 & $-35 \mathrm{dBm}$ & $-36 \mathrm{dBm}$ & $-32 \mathrm{dBm}$ \\
\hline 4 & $-36 \mathrm{dBm}$ & $-37 \mathrm{dBm}$ & $-35 \mathrm{dBm}$ \\
\hline 7 & $-40 \mathrm{dBm}$ & $-39 \mathrm{dBm}$ & $-42 \mathrm{dBm}$ \\
\hline
\end{tabular}

Berdasarkan hasil pengujian tersebut, antena mikrostrip array dua elemen mempunyai daya terima yang lebih baik dibandingkan antena 
mikrostrip elemen tunggal. Sedangkan antena mikrostrip elemen tunggal mempunyai daya terima yang lebih kecil daripada antena dipole. Semakin besar nilai gain antena maka semakin baik level sinyal daya terimanya.

\section{KESIMPULAN}

Antena mikrostrip yang telah dirancang bangun adalah antena mikrostrip patch persegi panjang elemen tunggal dan array dua elemen. Pengukuran antena menghasilkan nilai VSWR dan return loss pada frekuensi tengah $2,45 \mathrm{GHz}$ untuk antena mikrostrip patch persegi panjang elemen tunggal masing-masing sebesar 1,055 dan -31,444 dB, sedangkan untuk array dua elemen masing-masing sebesar 1,036 dan 34,929 dB. Bandwidth antena mikrostrip patch persegi panjang elemen tunggal sebesar 100 $\mathrm{MHz}$ pada rentang frekuensi $2,4-2,5 \mathrm{GHz}$, sedangkan array dua elemen bandwidth-nya 150 $\mathrm{MHz}$ pada rentang frekuensi 2,35 - 2,5 GHz. Gain antena mikrostrip patch persegi panjang elemen tunggal adalah sebesar 3,9 dB dan array dua elemen sebesar 6,67 dB. Dengan demikian antena array yang telah dirancang dapat meningkatkan nilai gain, bandwidth dan memperbaiki nilai VSWR serta return loss.

\section{DAFTAR PUSTAKA}

[1] IEEE 802.11: Wireless LAN Medium Access Control (MAC) and Physical Layer (PHY) Specifications (2012 Revision). IEEE-SA (2012)

[2] Balanis, C.A.,Antenna Theory: Analysis and Design, ed. 3, John Willey and Son, USA (2005)

[3] Stutzman, W.L. \& Thiele, G.A., Antenna Theory and Design, ed. 2, John Willey, USA (1998)

[4] Pasaribu, D. \& Rambe, A. H., Rancang Bangun Antena Mikrostrip Patch Segiempat pada Frekuensi 2,4 $\mathrm{GHz}$ dengan Metode Pencatuan Inset, Jurnal Singuda Ensikom 7, no. 1, 30-35 (2014)

[5] Uli, W. F., Rambe, A.H., Rancang Bangun Patch Rectangular Antenna 2.4 $\mathrm{GHz}$ dengan Metode Pencatuan EMC (electromagnetically coupled), Jurnal Singuda Ensikom 6, no. 2, 81-86 (2014)
[6] Firmansyah, T., Purnomo, S., Fatonah, F., Nugroho, T.H.F., Antena Mikrostrip Rectangular Patch 1575,42 MHz dengan Polarisasi Circular untuk Receiver GPS, Jurnal Nasional Teknik Elektro dan Teknologi Informasi 4, no. 4 (2015)

[7] Darsono, M., Rancang Bangun Antena Mikrostrip Dua Elemen Patch Persegi Untuk Aplikasi WirelessFidelity, Jurnal EECCIS 6, no. 2, 171-176 (2012)

[8] Herudin, Amir, M. A., Alimuddin, Rancang Bangun Antena Mikrostrip Biquad Ganda untuk Aplikasi Wi-Fi, Jurnal Nasional Teknik Elektro 3, no. 1, 44-53 (2014)

[9] James, J.R., Hall P.S., Handbook of Microstrip Antennas, Peter Peregrinus Ltd. Vol. I and II (1993)

[10] David M. Pozar, Microwave Engineering, John Willey and Son (2001)

[11] Ramesh, M., \& KB, Yip., Design Formula for Inset Fed Mikrostrip, Journal of Microwaves and Optoelectronics 3, no.3, 5-10 (2003)

\section{Biodata Penulis}

Eva Yovita Dwi Utami, memperoleh gelar Sarjana Teknik dari jurusan Teknik Elektro Sekolah Tinggi Teknologi Telkom, Bandung dan gelar Magister Teknik dari Departemen Teknik Elektro Universitas Indonesia. Saat ini sebagai staf pengajar program studi Teknik Elektro Universitas Kristen Satya Wacana, Salatiga dengan minat penelitian dalam bidang Komunikasi Nirkabel dan Antena dan Propagasi.

F. Dalu Setiaji, menamatkan S1 di Universitas Kristen Satya Wacana (UKSW), Salatiga pada tahun 1996. Pendidikan S2 diselesaikan di Teknik Elektro Universitas Gadjah Mada pada tahun 2006. Saat ini sebagai staf pengajar program studi Teknik Elektro Universitas Kristen Satya Wacana, Salatiga dengan bidang peminatannya adalah untai mikroelektronika dan sistem adaptif.

Daniel Pebrianto, memperoleh gelar Sarjana Teknik dari program studi Teknik Elektro Universitas Kristen Satya Wacana, Salatiga. 